CNS Spectrums (2017), 22, 475-483. C Cambridge University Press 2017. This is an Open Access article, distributed under the terms of the Creative Commons Attribution licence (http:/ / creativecommons.org/licenses/by/4.0/), which permits unrestricted re-use, distribution, and reproduction in any medium, provided the original work is properly cited.

\title{
Measures of suicidality in phase 3 clinical trials of levomilnacipran ER in adults with major depressive disorder
}

\author{
Michael E. Thase, ${ }^{1 *}$ Carl Gommoll, ${ }^{2}$ Changzheng Chen, ${ }^{2}$ Kenneth Kramer, ${ }^{2}$ \\ Arif Khan, ${ }^{3,4}$ and Suresh Durgam ${ }^{2}$
}

\footnotetext{
${ }^{1}$ Department of Psychiatry, Perelman School of Medicine, University of Pennsylvania, Philadelphia, Pennsylvania, USA

${ }^{2}$ Allergan, Jersey City, New Jersey, USA

${ }^{3}$ Northwest Clinical Research Center, Bellevue, Washington, USA

${ }^{4}$ Department of Psychiatry, Duke University School of Medicine, Durham, North Carolina, USA
}

Objective. To evaluate the effects of levomilnacipran extended-release (ER) on suicidal ideation and behavior in adults with major depressive disorder (MDD).

Methods. Post hoc analyses were conducted in patients from 4 randomized, double-blind, placebo-controlled trials and a long-term, open-label extension study of levomilnacipran ER (40-120 mg/d) in adults with MDD. Analyses included incidence of suicide-related treatment-emergent adverse events (TEAEs); incidence of Columbia-Suicide Severity Rating Scale (C-SSRS) suicidal ideation (score =1-5) and behavior (score = 6-10); percent of patients who shifted from no C-SSRS suicidal ideation/behavior at baseline to suicidal ideation during treatment (worsened from score $=0$ to score $=1-5)$, or vice-versa (improved from score $=1-5$ to score $=0$ ).

Results. Suicide-related TEAEs occurred in $<1 \%$ of patients in the levomilnacipran ER studies. The incidence of C-SSRS suicidal ideation was $22.2 \%, 23.9 \%$, and $21.7 \%$ for placebo, short-term levomilnacipran ER, and long-term levomilnacipran ER, respectively; C-SSRS suicidal behavior was $<1 \%$ in all of these groups. In the short-term studies, the percentage of patients with C-SSRS shifts were as follows: worsening from score $=0$ to score $=1-5$ (placebo, 8.6\%; levomilnacipran ER, 11.0\%); improvement from score = 1-5 to score = 0 (placebo, 24.0\%; levomilnacipran ER, $27.7 \%$ ).

Conclusion. In adult MDD patients, the incidence of suicidal ideation and behavior was similar between placebo and short-term levomilnacipran ER as indicated by TEAE reports and C-SSRS scores. Worsening in C-SSRS scores was also similar between placebo and levomilnacipran ER. There was no indication of increased suicidality during longer courses of continued therapy. Together, these findings suggest that this medication is not associated with increased risks of suicidal ideation or behavior.

Received 5 April 2016; Accepted 22 August 2016; First published online 19 May 2017

Key words: Adverse events, antidepressant, clinical trial, major depressive disorder, post hoc analysis, suicidal behavior, suicidal ideation.

\section{Introduction}

Suicide accounts for an estimated $1.5 \%$ of the global burden of disease, with psychiatric disorders contributing

\footnotetext{
* Address for correspondence: Michael E. Thase, MD, Professor of Psychiatry, Director, Mood and Anxiety Program, University of Pennsylvania Health System, 3535 Market Street, Mezzanine, Philadelphia, PA 19104, USA.

(Email: thase@mail.med.upenn.edu)

Writing and editorial support was provided by Mildred Bahn at Prescott Medical Communications Group (Chicago, IL, USA), a contractor of Allergan.
}

to approximately $90 \%$ of suicides; mood disorders (primarily major depressive disorder [MDD]) account for approximately $60 \%$ of suicides. ${ }^{1}$ A Canadian Community Health Study survey found that in respondents who had MDD, the 12-month prevalence of suicidal ideation, suicide plan, and suicide attempt was $26.9 \%$, $12.0 \%$, and $6.6 \%$, respectively. ${ }^{2}$ Similar estimates were found in the United States (US) National Survey on Drug Use and Health (NSDUH) study, which reported a 12-month prevalence of suicidal ideation of $26.3 \%$ in adults with MDD. ${ }^{3}$ The 12-month prevalence of suicide attempt among MDD respondents in the NSDUH 
study varied based on whether they had prior ideation without a suicide plan $(4.4 \%)$ or with a suicide plan $(32.9 \%)^{4}$ Findings from the NSDUH study were consistent with other studies that found prior suicidal ideation to be strong predictors of subsequent suicide attempt. $^{5-7}$

In patients who have suicidal ideation or behavior as part of their MDD symptomatology, antidepressants can help to reduce these symptoms. However, there is ongoing concern about the emergence of suicidal thoughts and behaviors as an adverse effect of treatment. For example, although antidepressant clinical trials typically exclude patients who may be at risk for suicide, suicide-related events still occur, albeit at very low incidences. ${ }^{8-10}$ Based on meta-analyses of clinical trials conducted in pediatric populations and younger adults (18-24 years of age), ${ }^{11,12}$ a black-box warning for increased risk of suicidal ideation and behavior in these populations is now required by the US Food and Drug Administration (FDA) for all approved antidepressants. The relationship between antidepressants and treatmentemergent suicidality in older adults is less clear. Some meta-analyses have found an increased risk of suicidality with antidepressants, particularly with older serotonin reuptake inhibitors, ${ }^{13-15}$ while other meta-analyses found no increased risk of suicide-related events in older adults. ${ }^{12,16}$ Nonetheless, prescribing information for FDA-approved antidepressants generally recommends that all patients treated with these medications continue to be monitored for the emergence of suicidal thoughts or behaviors.

Despite the understandable desire to warn clinicians, patients, and the general public about the serious possibility of treatment-related suicidality, the FDA black-box warning may have had some unintended consequences. A study using data from 11 geographically distributed US healthcare organizations found that in the second year following implementation of the FDA warning, the relative decrease in antidepressant use was $24.3 \%$ in young adults (18-29 years of ages) and $14.5 \%$ in adults (30-64 years). ${ }^{17}$ In the same time frame, the relative increase in suicide attempts (as measured by nonfatal drug poisoning) was $33.7 \%$ in young adults and $5.2 \%$ in adults, which may have been an underestimate since other suicidal behaviors were not included in the analysis. The results of this study suggest that media coverage of the FDA warning may have had unforeseen negative effects, and as the authors of the study conclude, more research and better education are needed to clarify both the risks and benefits of antidepressant treatment in patients who require such therapy.

One such effort has been the development of an FDA consensus statement that emphasizes the importance of differentiating between suicidal ideation and suicidal behavior in pharmacotherapy clinical trials. ${ }^{18}$
The consensus statement adheres to recommendations of the Columbia Classification Algorithm of Suicide Assessment (C-CASA) and endorses use of the validated Columbia-Suicide Severity Rating Scale (C-SSRS) in clinical trials. The C-SSRS was specifically developed to quantify the severity of suicidal ideation and behavior following C-CASA guidelines. ${ }^{19,20}$ As recommended, the C-SSRS was used in addition to adverse event (AE) reporting to monitor suicidal ideation and behavior in 4 US clinical trials of levomilnacipran extendedrelease (ER), ${ }^{21-24}$ a selective serotonin and norepinephrine reuptake inhibitor that is approved for the treatment of MDD in adults. Since it is difficult to ascertain the effects of any medication on relatively uncommon events such as suicidal ideation or behavior, ${ }^{12}$ the $\mathrm{AE}$ and C-SSRS data from these trials were pooled to examine suicidality from a larger sample of patients. Post hoc analyses of these pooled data were conducted to investigate the emergence of treatment-related suicidal ideation and behavior in adults with MDD.

\section{Methods}

\section{Clinical studies}

Post hoc analyses were conducted using data from 4 short-term trials and 1 long-term, open-label extension study of levomilnacipran ER in adults with MDD. Methods for these studies have been previously reported. ${ }^{21-25}$

The 4 short-term, randomized, double-blind, placebocontrolled studies were conducted at multiple study sites throughout the US. They included 2 fixed-dose trials $\left(40,80\right.$, or $120 \mathrm{mg} / \mathrm{d}$ [NCT00969709 ${ }^{21}$ ]; 40 or $80 \mathrm{mg} / \mathrm{d}$ [NCT01377194 ${ }^{22}$ ]) and 2 flexible-dose trials (40$120 \mathrm{mg} / \mathrm{d}$ [NCT00969150 23 and NCT01034462 24 ]) in which patients received 8 weeks of double-blind treatment. Eligible patients from 3 of these studies ${ }^{21,23,24}$ participated in the long-term, open-label extension study $\left(\mathrm{NCT} 01034267^{25}\right)$ in which they received 48 weeks of flexible-dose treatment with levomilnacipran ER (40-120 mg/d).

All of the short-term studies included men and women, ages 18 to 80 years, who met Diagnostic and Statistical Manual of Mental Disorders, 4th Edition, Text Revision (DSM-IV-TR) criteria for MDD. All patients were required to have a current major depressive episode and a Montgomery-Åsberg Depression Rating Scale (MADRS) total sore $\geq 30^{21,23,24}$ or $\geq 26 .{ }^{22}$ Patients with a DSM-IV-TR-based diagnosis of an Axis I disorder other than MDD within 6 months prior to screening were ineligible for study entry. Other key exclusion criteria were history of nonresponse to $\geq 2$ antidepressants after adequate treatment duration at recommended dosages and current suicide risk, based on suicide 
attempt within the past year, score $\geq 5$ on MADRS suicidal thoughts item, C-SSRS responses, and/or investigator judgment.

\section{Post hoc analyses}

Post hoc analyses of the short-term studies were conducted in the pooled safety population, defined as all randomized patients who received $\geq 1$ dose of doubleblind study medication. All levomilnacipran ER dosage groups were pooled for these analyses, with no inferential statistics conducted for comparisons between levomilnacipran ER and placebo. Some analyses were also conducted in the long-term safety population, which included all patients in the extension study who received $\geq 1$ dose of open-label treatment.

The incidence of suicidal ideation and behavior was summarized for the pooled and long-term safety populations. For suicide-related treatment-emergent adverse events (TEAEs), incidence was analyzed based on the following Medical Dictionary for Regulatory Activities (MedDRA)-preferred terms: completed suicide, depression suicidal, intentional overdose (or overdose), intentional self-injury, multiple drug overdose intentional, poisoning deliberate, self-injurious behavior, selfinjurious ideation, suicidal behavior, suicidal ideation, and suicide attempt. For C-SSRS-based incidences, suicidal ideation was defined as a "yes" response in any ideation category (C-SSRS score of 1-5); suicidal behavior was defined as a "yes" response in any behavior category (C-SSRS score of 6-10). The incidence of suicidal ideation or behavior was based on each patient's maximum C-SSRS score during treatment (ie, at any study visit). In addition to overall incidence, C-SSRS suicidal ideation in the short-term studies was summarized at all double-blind study visits in patients with available assessments at each respective visit; this analysis was conducted in the pooled safety population and in a subgroup of younger adult patients ( $\leq 24$ years of age).

C-SSRS shifts were analyzed in the pooled safety population and in younger adults based on each patient's C-SSRS score at baseline and maximum C-SSRS score during double-blind treatment. The shifts were classified as follows: no change (eg, no suicidal ideation/behavior [score of 0] at baseline and throughout treatment); worsening (eg, shift from suicidal ideation [score of 1-5] at baseline to suicidal behavior [score of 6-10]); and improvement (eg, shift from suicidal ideation at baseline [score of 1-5] to no ideation/behavior [score of 0 ]). Analyses were also conducted using 2 definitions from the C-SSRS Scoring and Data Analysis Guide (C-SSRS Guide $)^{26}$ : (1) treatment-emergent suicidal ideation, defined as any suicidal ideation score during doubleblind treatment that was greater than the baseline
C-SSRS score; and (2) emergence of serious suicidal ideation, defined as an increase from a baseline score of 0 to a maximum score of 4-5 at any time during treatment. The C-SSRS shift and C-SSRS Guide analyses were limited to patients whose baseline scores were based on recent history (ie, not lifetime history).

\section{Results}

\section{Patients}

In the pooled safety population, patient demographics were generally similar between the placebo and levomilnacipran ER groups (Table 1). Based on self-reported psychiatric history, $13.0 \%(268 / 2066)$ of patients had attempted suicide at some point in their lifetime; no patient had attempted suicide for at least 1 year prior to study entry. C-SSRS assessments at screening indicated that $50.3 \%(1039 / 2066)$ had a lifetime history of suicidal ideation and $19.2 \%(396 / 2066)$ had a lifetime history of suicidal behavior, which was consistent with the high percentage of patients ( $>\mathbf{8 0 \%}$ ) with recurrent depressive episodes.

\section{Incidence of suicidal ideation and behavior}

No suicide-related TEAE occurred in $\geq 1 \%$ of patients who received placebo or levomilnacipran ER, either during short-term or long-term treatment (Table 2).

\begin{tabular}{|c|c|c|}
\hline Characteristics & $\begin{array}{l}\text { Placebo } \\
\mathrm{n}=761\end{array}$ & $\begin{array}{l}\text { Levomilnacipran ER } \\
\qquad n=1305\end{array}$ \\
\hline \multicolumn{3}{|l|}{ Demographics } \\
\hline Age, mean (SD), years & $43.0(13.0)$ & $42.5(12.9)$ \\
\hline Age, median (range), years ${ }^{a}$ & $44.0(18,78)$ & $43.0(18,74)$ \\
\hline Age $\leq 24$ years, $n(\%)$ & $67(8.8)$ & $129(9.9)$ \\
\hline Women, n (\%) & $483(63.5)$ & $819(62.8)$ \\
\hline White, $n(\%)$ & $600(78.8)$ & $983(75.3)$ \\
\hline Body mass index, mean (SD), $\mathrm{kg} / \mathrm{m}^{2}$ & $29.1(5.5)$ & $28.7(5.4)$ \\
\hline \multicolumn{3}{|c|}{ Patient-reported psychiatric history } \\
\hline MDD duration, mean (SD), years & $12.9(11.4)$ & $12.0(11.2)$ \\
\hline Recurrent episodes, n (\%) & $648(85.2)$ & $1069(81.9)$ \\
\hline $\begin{array}{l}\text { Current episode duration, mean } \\
\text { (SD), months }\end{array}$ & $14.5(35.4)$ & $14.8(39.1)$ \\
\hline Attempted suicide in lifetime, $\mathrm{n}(\%)$ & $110(14.5)$ & $158(12.1)$ \\
\hline Attempted suicide in past year, $\mathrm{n}$ & 0 & 0 \\
\hline \multicolumn{3}{|l|}{$\begin{array}{l}\text { Baseline C-SSRS assessment, lifetime } \\
\text { history }\end{array}$} \\
\hline Suicidal ideation, n (\%) & $378(49.7)$ & $661(50.7)$ \\
\hline Suicidal behavior, n (\%) & $150(19.7)$ & $246(18.9)$ \\
\hline $\begin{array}{l}{ }^{a} \text { Range reflects the minimum and } \mathrm{m} \\
\text { study population. } \\
\text { C-SSRS, Columbia-Suicide Severity } \\
\text { major depressive disorder; SD, standard }\end{array}$ & $\begin{array}{l}\text { Rating Scale; E| } \\
\text { deviation. }\end{array}$ & $\begin{array}{l}\text { patients in this poolec } \\
\text { extended-release; MDD }\end{array}$ \\
\hline
\end{tabular}


Per investigator judgment, 4 patients with a TEAE of "suicidal ideation" (1 placebo, 3 levomilnacipran ER) and 1 patient with "suicidal behavior" (preparatory acts) were withdrawn from the short-term studies. One patient receiving levomilnacipran ER with TEAEs of "suicide attempt" and "intentional overdose" was also withdrawn. In the open-label extension study, 2 patients with a TEAE for "suicidal ideation" and 4 patients with "suicide attempt" (including 2 patients with "overdose") were discontinued from the study.

The incidence of any C-SSRS suicidal ideation during double-blind treatment was similar between the placebo and levomilnacipran ER groups $(22.2 \%$ and $23.9 \%$, respectively); the incidence was not higher in the longterm open-label treatment with levomilnacipran ER (Table 2). The incidence of any suicidal behavior was $<0.5 \%$ in all treatment groups, including long-term levomilnacipran ER. No completed suicides occurred during any of the studies.
The incidence of C-SSRS suicidal ideation in the pooled safety population decreased steadily over the course of double-blind treatment with both levomilnacipran ER and placebo (Figure 1A). No similar pattern was detected in younger adult patients, although the incidence of suicidal ideation was lower at Week 8 than at baseline in both treatment groups (Figure 1B).

\section{Analyses of C-SSRS category shifts}

In both treatment groups of the pooled safety population, approximately $90 \%$ of patients who had a C-SSRS score of 0 at baseline continued to have no suicidal ideation/behavior throughout double-blind treatment (Table 3). Shifting from a baseline score of 0 to a maximum score of 1-5 during double-blind treatment (ie, worsening from no ideation/ behavior to suicidal ideation) occurred less frequently in both treatment groups than shifting from a score of 1-5 to a score of 0 (ie, improvement from suicidal ideation to no

TABLE 2. Incidence of suicidal ideation or behavior (pooled safety population and long-term safety population)

\begin{tabular}{|c|c|c|c|}
\hline & \multicolumn{2}{|c|}{$\begin{array}{l}\text { Randomized controlled trials } \\
\text { (8 weeks) }\end{array}$} & \multirow{2}{*}{$\begin{array}{c}\begin{array}{c}\text { Extension study } \\
(48 \text { weeks })\end{array} \\
\text { Levomilnacipran } \\
\mathrm{N}=825\end{array}$} \\
\hline & $\begin{array}{l}\text { Placebo } \\
\mathrm{n}=761\end{array}$ & $\begin{array}{l}\text { Levomilnacipran ER } \\
\qquad \mathrm{n}=1305\end{array}$ & \\
\hline \multicolumn{4}{|l|}{ TEAEs, $n(\%)^{a, b}$} \\
\hline Suicidal ideation & $2(0.3)$ & $4(0.3)$ & $4(0.5)$ \\
\hline Suicidal behavior & $1(0.1)$ & $1(<0.1)$ & $1(0.1)$ \\
\hline Suicide attempt & 0 & $1(<0.1)$ & $4(0.5)$ \\
\hline Intentional overdose/overdose ${ }^{c}$ & 0 & $1(<0.1)$ & $2(0.2)$ \\
\hline \multicolumn{4}{|l|}{ C-SSRS, n (\%) $)^{d}$} \\
\hline Any suicidal ideation & $169(22.2)$ & $312(23.9)$ & $179(21.7)$ \\
\hline Any suicidal behavior & $1(0.1)$ & $5(0.4)$ & $3(0.4)$ \\
\hline \multicolumn{4}{|l|}{ Serious suicidal ideation and suicidal behaviors } \\
\hline $\begin{array}{l}\text { Active suicidal ideation with some intent to act; without specific plan } \\
\text { (maximum score of 4) }\end{array}$ & $5(0.7)$ & $7(0.5)$ & $7(0.9)$ \\
\hline $\begin{array}{l}\text { Active suicidal ideation with specific plan and intent } \\
\text { (maximum score of } 5 \text { ) }\end{array}$ & $2(0.3)$ & $4(0.3)$ & $2(0.2)$ \\
\hline $\begin{array}{l}\text { Preparatory acts or behavior } \\
\text { (maximum score of } 6 \text { ) }\end{array}$ & $1(0.1)$ & $1(0.1)$ & 0 \\
\hline $\begin{array}{l}\text { Aborted/self-interrupted attempt } \\
\text { (maximum score of } 7 \text { ) }\end{array}$ & 0 & $1(0.1)$ & $2(0.2)$ \\
\hline $\begin{array}{l}\text { Interrupted attempt } \\
\text { (maximum score of 8) }\end{array}$ & 0 & 0 & 0 \\
\hline $\begin{array}{l}\text { Actual attempt } \\
\text { (maximum score of 9) }\end{array}$ & 0 & $3(0.2)$ & $1(0.1)$ \\
\hline $\begin{array}{l}\text { Completed suicide } \\
\text { (maximum score of } 10)\end{array}$ & 0 & 0 & 0 \\
\hline
\end{tabular}

${ }^{a}$ Patients were only counted once within each MedDRA preferred term. None of the following preferred terms were reported by patients in either treatment group during doubleblind treatment in the acute studies or during open-label treatment with levomilnacipran ER in the long-term extension study: completed suicide, depression suicidal, intentional self-injury, multiple drug overdose intentional, poisoning deliberate, self-injurious behavior, or self-injurious ideation.

${ }^{b}$ For the extension study, TEAEs included adverse events that were not present before the first dose of double-blind treatment in the lead-in study, or that were present before the first dose of double-blind treatment in the lead-in study, but that increased in intensity following the first dose of long-term, open-label treatment.

${ }^{c}$ Overdose not specified as intentional or accidental in the extension study.

${ }^{d}$ Only the most severe ideation type and the most severe suicidal behavior across all visits during the double-blind treatment period (randomized controlled trials) or open-label treatment period (extension study) were counted for each patient.

C-SSRS, Columbia-Suicide Severity Rating Scale; ER, extended-release; MedDRA, Medical Dictionary for Regulatory Activities; TEAE, treatment-emergent adverse event. 
A

All Patients, Ages $\geq 18$ to $\leq 80$ Years
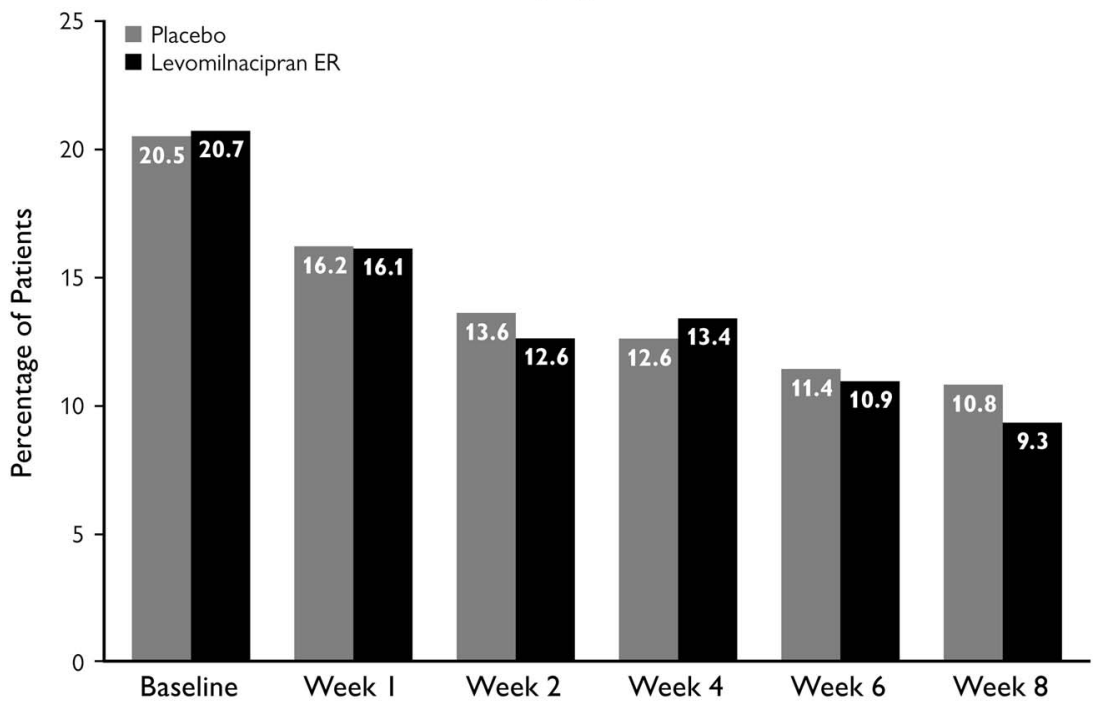

B

Younger Adult Patients, Ages $\leq 24$ Years

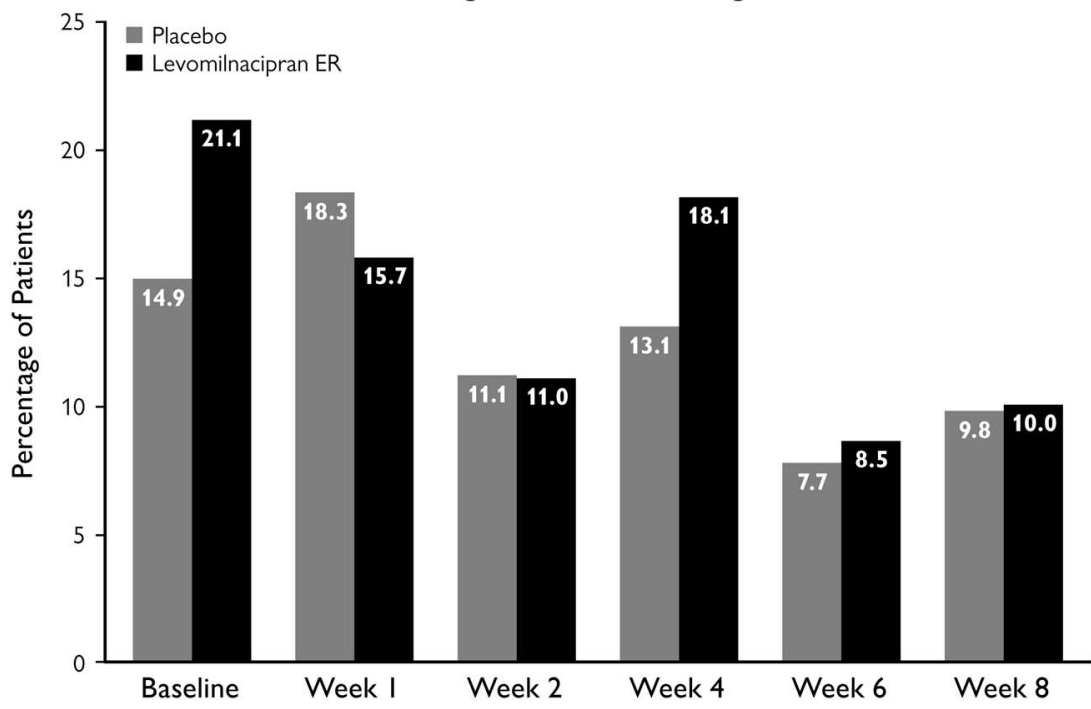

FIGURE 1. Incidence of C-SSRS suicidal ideation at study visits. Suicidal ideation was defined as a C-SSRS score of 1-5. Analyses were conducted in all patients from the pooled safety population and in a subset of younger adult patients, based on available C-SSRS assessments for each respective study visit. C-SSRS, Columbia-Suicide Severity Rating Scale; ER, extended-release.

ideation/behavior). A similar pattern of results was seen in the subset of younger adults $(\leq 24$ years).

One patient in each treatment group shifted from a baseline score of 0 to a maximum score of 6-10 during double-blind treatment (ie, worsening from no suicidal ideation to suicidal behavior). The levomilnacipran ER patient who met the criteria for this shift was in the younger age group; the placebo patient was not.

\section{Analyses based on C-SSRS Guide definitions}

In the pooled safety population, the incidence of treatment-emergent suicidal ideation (ie, any worsening in suicidal ideation score among patients with baseline
C-SSRS score of 0-4) was $10.5 \%$ and $12.6 \%$ for placebo and levomilnacipran ER, respectively. In younger adults, the incidence for placebo and levomilnacipran ER was $13.4 \%$ and $15.6 \%$, respectively.

The incidence of emergent serious suicidal ideation (ie, baseline C-SSRS score of 0 and maximum score of 4-5 during double-blind treatment) was $0.3 \%$ for both placebo and levomilnacipran ER. One of these patients (treated with levomilnacipran ER) was $\leq 24$ years old.

\section{Discussion}

Analyses of pooled data from 4 short-term, randomized, double-blind, placebo-controlled trials suggest that therapy 
TABLE 3. C-SSRS category shifts ${ }^{a}$

\begin{tabular}{|c|c|c|c|c|}
\hline & \multicolumn{2}{|c|}{$\begin{array}{c}\text { All patients } \\
\text { ages } \geq 18 \text { to } \leq 80 \text { years }\end{array}$} & \multicolumn{2}{|c|}{$\begin{array}{c}\text { Younger adult patients } \\
\text { ages } \leq 24 \text { years }\end{array}$} \\
\hline & Placebo & Levomilnacipran ER & Placebo & Levomilnacipran ER \\
\hline Number of patients with no suicidal ideation/behavior at baseline ${ }^{b}$ & 593 & 1010 & 57 & 101 \\
\hline No change, n (\%) & $541(91.2)$ & $898(88.9)$ & $49(86.0)$ & $87(86.1)$ \\
\hline Worsened to suicidal ideation, $\mathrm{n}(\%)$ & $51(8.6)$ & $111(11.0)$ & $8(14.0)$ & $13(12.9)$ \\
\hline Worsened to suicidal behavior, n (\%) & $1(0.2)$ & $1(0.1)$ & $0(0.0)$ & $1(1.0)$ \\
\hline Number of patients with suicidal ideation at baseline ${ }^{b}$ & 150 & 264 & 10 & 27 \\
\hline No change, $n(\%)$ & $114(76.0)$ & $187(70.8)$ & $8(80.0)$ & $18(66.7)$ \\
\hline Worsened to suicidal behavior, $\mathrm{n}(\%)$ & $0(0.0)$ & $4(1.5)$ & $0(0.0)$ & $0(0.0)$ \\
\hline Improved to no ideation/behavior, $\mathrm{n}(\%)$ & $36(24.0)$ & $73(27.7)$ & $2(20.0)$ & $9(33.3)$ \\
\hline
\end{tabular}

${ }^{a}$ Categories defined as follows based on C-SSRS scores: no suicidal ideation/behavior (score $=0$ ); suicidal ideation ( $($ core $=1-5$ ); suicidal behavior $($ score $=6-10$ ).

${ }^{b}$ Number of patients with a relevant baseline C-SSRS score (based on recent history only) and $\geq 1$ available post-baseline C-SSRS assessment.

C-SSRS, Columbia-Suicide Severity Rating Scale; ER, extended-release; $n=$ number of patients with available baseline and $\geq 1$ post-baseline C-SSRS assessment.

with levomilnacipran ER was not associated with an increased risk of suicidal ideation or behavior in adults with MDD who were not at risk for suicide prior to treatment. The incidence of suicide-related TEAEs in the pooled safety population was low and similar between the placebo and levomilnacipran ER groups $(<1 \%$ for any TEAE in both groups), although it is possible that suicide-related TEAEs were under-reported in all treatment groups. These results were consistent with findings from an FDA-sponsored meta-analysis that included 372 randomized and placebo-controlled trials of antidepressants from different classes. ${ }^{12}$ In this meta-analysis, any suicidal ideation or behavior (suicide preparation, attempt, or completion) was reported in $<1 \%$ of patients with major depression (placebo, 0.8\%; antidepressant, $0.7 \%$ ), with the estimated odds ratio (OR) for these events indicating a lower risk with antidepressants, although the comparison was not statistically significant $(\mathrm{OR}=0.85 ; 95 \%$ confidence interval [CI], 0.67-1.07; $P=0.16)$. Statistical analyses were not conducted for the data presented in this report, but it would be surprising if there were any statistical differences between levomilnacipran ER and the placebo for the low incidences of suiciderelated TEAEs found in these pooled studies (Table 2).

One issue raised by the FDA meta-analysis is that longterm antidepressant treatment may have a different effect on suicide-related events than acute treatment, with maintenance treatments potentially providing protective effects that would reduce the long-term risk of suicidal ideation and behavior. ${ }^{12}$ It is difficult to draw definitive conclusions based on data from a single openlabel study, but the incidence of suicide-related TEAEs in patients who received 48 weeks of levomilnacipran ER at flexible doses $(<1 \%$ for any TEAE) was similar to those found in patients who received acute treatment with either levomilnacipran ER or placebo. The results were also similar to those of other long-term antidepressants, ${ }^{27}$ but much more research is needed to better understand how medications used for relapse prevention or the treatment of chronic MDD may affect the risk of suicidal ideation or behavior.

In accordance with FDA safety guidelines, ${ }^{18}$ the C-SSRS was used along with AE reporting to monitor suicidality. To capture the most severe ideation or behavior experienced by each patient, incidence was based on the maximum C-SSRS score reported at any study visit during treatment. The incidence of C-SSRS suicidal ideation was similar between placebo and levomilnacipran ER ( $22.2 \%$ and $23.9 \%$, respectively) in the short-term studies; a similar incidence for levomilnacipran ER (21.7\%) was observed in the long-term study. In all of these treatment groups, however, $>95 \%$ of the patients with suicidal ideation had C-SSRS scores of 1-3, representing a general wish to be dead, active but nonspecific suicidal thoughts, or active suicidal thoughts without methods or intent to act. Serious suicidal ideation (as defined in the C-SSRS Guide ${ }^{26}$ as scores of 4-5) and suicidal behavior (C-SSRS scores of 6-10) were found in $<1 \%$ of patients in the short-term studies (levomilnacipran ER or placebo) and in $<1 \%$ of patients in the long-term study. Comparing the incidences of suicidal ideation and behavior based on C-SSRS responses and $\mathrm{AE}$ reporting points to the differences in these methodologies. As intended, the C-SSRS provided a more granular perspective on the types of suicidal thoughts and behaviors that patients experienced during antidepressant treatment. Especially for nonserious suicidal ideation, the C-SSRS was more sensitive in the levomilnacipran ER studies for detecting the suiciderelated events, possibly due to patients being prompted to talk about suicidality in contrast to being asked a general question about adverse effects. From a clinical 
standpoint, these findings suggest that using explicit language to monitor suicidality may help increase awareness of nonspecific and nonintentional suicidal ideation before such thoughts become more severe and possibly develop into suicidal behaviors.

As there is an ongoing concern about increased risks of treatment-emergent suicidality in younger adults, ${ }^{12}$ we took a close look at C-SSRS results in patients who were $\leq 24$ years of age. The results from these analyses generally indicate that treatment with levomilnacipran ER did not pose a greater risk of suicidal ideation or behavior in younger adults. Over the course of doubleblind treatment, younger adult patients in the levomilnacipran ER studies did not have the same pattern of steady decline in incidence of C-SSRS suicidal ideation as was seen in the overall pooled safety population (Figure 1). However, despite an increase at Week 4 with levomilnacipran ER (18.1\%) in younger adults, the overall decline in incidence from baseline to Week 8 was somewhat larger in the levomilnacipran ER group $(21.1 \%$ to $10.0 \%)$ than in the placebo group $(14.9 \%$ to $9.8 \%$ ). Given the relatively small number of younger patients (placebo, $\mathrm{n}=67$; levomilnacipran $\mathrm{ER}, \mathrm{n}=128$ ), it is difficult to draw any strong conclusions about this subgroup. However, the increase at Week 4 with levomilnacipran ER suggests that clinicians may want to be especially vigilant during the first few weeks of treatment in their monitoring of suicidal ideation. Although the Week 4 increase in younger adults mostly represented patients with nonspecific and nonintentional suicidal thoughts (C-SSRS score of 1-3), it did include a few patients with active suicidal ideation (with intent and plan). Identifying such patients-even if relatively few in number-is extremely important, since those with a plan are much more likely to attempt suicide than those without a plan. ${ }^{4}$

Analyses based on C-SSRS category shifts also indicated that the risk of suicidal ideation and behavior was not greater with levomilnacipran ER than with placebo. In fact, a higher percentage of levomilnacipran ER-treated patients improved from suicidal ideation at baseline (C-SSRS score of 1-5) to no ideation/ behavior (C-SSRS score of 0) during double-blind treatment, although the absence of statistical testing and the very small sample size in younger patients $(\mathrm{n}=37)$ needs to be considered when interpreting these results.

The analyses based on C-SSRS Guide definitions for treatment-emergent suicidal ideation and emergence of serious suicidal ideation were conducted to evaluate whether patients treated with levomilnacipran ER had a general worsening in suicidal thoughts or sudden development of active suicidal thoughts with intent and possible plan. The percentage of patients who met either of these definitions was similar between levomilnacipran
ER and placebo in the pooled safety population and in the younger adult patients. The incident of emergent serious suicidal ideation was $0.3 \%$ in both treatment groups, which was consistent with $\mathrm{AE}$ reporting for suicidal ideation (also $0.3 \%$ of patients both treatment groups). Again, although these percentages only represent a small number of patients, they highlight the need to actively elicit information about suicidal thoughts and to pay attention to any voluntary information provided by patients regarding such thoughts. In these cases, a careful assessment of each patient's individual situation is needed to decide upon an optimal course of action, such as adding or increasing behavioral therapy, changing dosage of the current medication, or switching to a different class of antidepressant drugs.

\section{Limitations}

Although pooling data from multiple studies allows for post hoc analysis of a bigger sample, assessing the risk of suicidality based on uncommon TEAEs such as suicidal ideation and suicidal behavior is challenging. ${ }^{12,18}$ However, implementation of the C-SSRS in the levomilnacipran ER trials helped to provide a broader perspective on suicide-related events, mostly by helping to identify patients with nonspecific and nonintentional suicide ideation. Monitoring suicidal thoughts and behaviors with this instrument resulted in higher incidences of any suicidal ideation (C-SSRS score of 1-5) relative to $\mathrm{AE}$ reporting in both treatment groups, but the similarity between levomilnacipran ER and placebo for C-SSRS suicidal ideation supported the overall conclusion that suicide-related events were not more common with active treatment.

The findings presented in this report are also limited by the exclusion of patients who were judged to be at-risk for suicide at screening, patients with concurrent major psychiatric disorders, and patients with alcohol/ substance abuse disorders. Therefore, no conclusions can be drawn regarding the effects of levomilnacipran ER on suicidal ideation or behavior in these types of patients. In addition, no adjustments were made for other factors that might affect suicidal risks, such as demographics (sex, age), MDD history (age of onset, number of major episodes, prior hospitalizations), socioeconomic status (income, employment, education), religion, family history, and childhood trauma. ${ }^{28-32}$ Given the small number of reported suicide-related events in the levomilnacipran ER studies, adjusting for such factors would probably not have been meaningful. However, continued research in the general population or with much larger databases is warranted to better understand how these factors affect the relationship between antidepressant treatment and suicide, both in terms of risk and potential benefits. 


\section{Conclusions}

Based on both AE reporting and C-SSRS scores from 4 short-term, randomized, double-blind, placebocontrolled trials, the incidences of suicidal ideation and suicidal behavior were similar between levomilnacipran ER $40-120 \mathrm{mg} / \mathrm{d}$ and placebo in adults with MDD. Suicidal ideation and behavior did not occur more frequently in the long-term, open-label extension study of levomilnacipran ER $40-120 \mathrm{mg} / \mathrm{d}$. Analyses based on shifts in C-SSRS scores and C-SSRS Guide definitions also indicated similar results between patients treated with short-term levomilnacipran ER and those who received placebo. Younger adult patients did not appear to have a greater risk of suicidal ideation or behavior as compared with the overall pooled safety population. However, regular monitoring of all patients, regardless of age, is recommended throughout treatment.

\section{Disclosures}

M. E. Thase has the following disclosures: Alkermes, consultant, personal fees; AstraZeneca, consultant, personal fees; Bristol-Myers Squibb Company, consultant, personal fees; Eli Lilly \& Co., consultant, grant recipient, grant/personal fees; Forest Laboratories, consultant, grant recipient, grant/personal fees; Gerson Lehman Group, consultant, personal fees; GlaxoSmithKline, consultant, personal fees; Guidepoint Global, consultant, personal fees; H. Lundbeck A/S, consultant, personal fees; MedAvante, consultant, personal fees, equity holdings; Merck and Co., consultant, personal fees; Neuronetics, Inc., consultant, personal fees; OrthoMcNeil Pharmaceuticals, consultant, personal fees; Otsuka, consultant, grant recipient, grant/personal fees; Pfizer, consultant, personal fees; Roche, consultant, personal fees; Shire US, Inc., consultant, personal fees; Sunovion Pharmaceuticals, Inc., consultant, personal fees; Takeda, consultant, personal fees; American Psychiatric Foundation, royalties; Guilford Publications, royalties; Herald House, royalties; W.W. Norton \& Company, Inc., royalties; Peloton Advantage, spouse's employment; Cerecor, Inc., consultant, personal fees; Moksha8, consultant, personal fees; Pamlab, L.L.C. (Nestle), consultant, personal fees; Allergan, consultant, personal fees; Trius Therapeutical, Inc., consultant, personal fees; Fabre-Kramer Pharmaceuticals, Inc., consultant, personal fees. A. Khan has been a principal investigator in more than 380 clinical trials sponsored by more than 65 pharmaceutical companies. He has not received any compensation as a consultant or speaker, nor does he own stock in any of these or other pharmaceutical companies. Dr. Khan has not been compensated for his role as an author on this or any other publication. C. Gommoll, C. Chen, K. Kramer, and S. Durgam are full-time employees of Allergan. Forest Research Institute, an Allergan affiliate, sponsored the clinical studies that are included in this report.

\section{REFERENCES:}

1. Mann JJ, Apter A, Bertolote J, et al. Suicide prevention strategies: a systematic review. JAMA. 2005; 294(16): 2064-2074.

2. Patten SB, Williams JV, Lavorato DH, et al. Descriptive epidemiology of major depressive disorder in Canada in 2012. Can J Psychiatry. 2015; 60(1): 23-30.

3. Han B, McKeon R, Gfroerer J. Suicidal ideation among communitydwelling adults in the United States. Am J Public Health. 2014; 104(3): 488-497.

4. Han B, Compton WM, Gfroerer J, McKeon R. Prevalence and correlates of past 12-month suicide attempt among adults with pastyear suicidal ideation in the United States. J Clin Psychiatry. 2015; 76(3): 295-302.

5. Oquendo MA, Galfalvy H, Russo S, et al. Prospective study of clinical predictors of suicidal acts after a major depressive episode in patients with major depressive disorder or bipolar disorder. Am J Psychiatry. 2004; 161(8): 1433-1441.

6. Perroud N, Uher R, Hauser J, et al. History of suicide attempts among patients with depression in the GENDEP project. J Affect Disord. 2010; 123(1-3): 131-137.

7. Mundt JC, Greist JH, Jefferson JW, et al. Prediction of suicidal behavior in clinical research by lifetime suicidal ideation and behavior ascertained by the electronic Columbia-Suicide Severity Rating Scale. J Clin Psychiatry. 2013; 74(9): 887-893.

8. Acharya N, Rosen AS, Polzer JP, et al. Duloxetine: meta-analyses of suicidal behaviors and ideation in clinical trials for major depressive disorder. J Clin Psychopharmacol. 2006; 26(6): 587-594.

9. Clayton AH, Kornstein SG, Rosas G, et al. An integrated analysis of the safety and tolerability of desvenlafaxine compared with placebo in the treatment of major depressive disorder. CNS Spectr. 2009 14(4): 183-195.

10. Baldwin DS, Chrones L, Florea I, et al. The safety and tolerability of vortioxetine: analysis of data from randomized placebo-controlled trials and open-label extension studies. J Psychopharmacol. 2016; 30(3): 242-252.

11. Hammad TA, Laughren T, Racoosin J. Suicidality in pediatric patients treated with antidepressant drugs. Arch Gen Psychiatry. 2006; 63(3): 332-339.

12. Stone M, Laughren T, Jones ML, et al. Risk of suicidality in clinical trials of antidepressants in adults: analysis of proprietary data submitted to US Food and Drug Administration. BMJ. 2009; 339: b2880.

13. Fergusson D, Doucette $\mathrm{S}$, Glass KC, et al. Association between suicide attempts and selective serotonin reuptake inhibitors: systematic review of randomised controlled trials. BMJ. 2005; 330(7488): 396.

14. Gunnell D, Saperia J, Ashby D. Selective serotonin reuptake inhibitors (SSRIs) and suicide in adults: meta-analysis of drug company data from placebo controlled, randomised controlled trials submitted to the MHRA's safety review. BMJ. 2005; 330 (7488): 385 .

15. Rubino A, Roskell N, Tennis $\mathrm{P}$, et al. Risk of suicide during treatment with venlafaxine, citalopram, fluoxetine, and dothiepin: retrospective cohort study. BMJ. 2007; 334(7587): 242.

16. Khan A, Khan S, Kolts R, Brown WA. Suicide rates in clinical trials of SSRIs, other antidepressants, and placebo: analysis of FDA reports. Am J Psychiatry. 2003; 160(4): 790-792. 
17. Lu CY, Zhang F, Lakoma MD, et al. Changes in antidepressant use by young people and suicidal behavior after FDA warnings and media coverage: quasi-experimental study. BMJ. 2014; 348: g3596.

18. Meyer RE, Salzman C, Youngstrom EA, et al. Suicidality and risk of suicide-definition, drug safety concerns, and a necessary target for drug development: a consensus statement. J Clin Psychiatry. 2010; 71(8): e1-e21.

19. Posner K, Oquendo MA, Gould M, et al. Columbia Classification Algorithm of Suicide Assessment (C-CASA): classification of suicidal events in the FDA's pediatric suicidal risk analysis of antidepressants. Am J Psychiatry. 2007; 164(7): 1035-1043.

20. Posner K, Brown GK, Stanley B, et al. The Columbia-Suicide Severity Rating Scale: initial validity and internal consistency findings from three multisite studies with adolescents and adults. Am J Psychiatry. 2011; 168(12): 1266-1277.

21. Asnis G, Bose A, Gommoll C, et al. The efficacy and safety of levomilnacipran SR $40 \mathrm{mg}, 80 \mathrm{mg}$, or $120 \mathrm{mg}$ in major depressive disorder: a phase III, randomized, double-blind, placebocontrolled study. J Clin Psychiatry. 2013; 74(3): 242-248.

22. Bakish D, Bose A, Gommoll C, et al. Levomilnacipran ER $40 \mathrm{mg}$ and $80 \mathrm{mg}$ in patients with major depressive disorder: a phase III, randomized, double-blind, fixed-dose, placebo-controlled study. J Psychiatry Neurosci. 2014; 39(1): 40-49.

23. Gommoll CP, Greenberg WM, Chen C. A randomized, double-blind, placebo-controlled study of flexible doses of levomilnacipran ER (40-120 mg/day) in patients with major depressive disorder. J Drug Assess. 2014; 3(1): 10-19.

24. Sambunaris A, Bose A, Gommoll C, et al. A phase III, double-blind, placebo-controlled, flexible-dose study of levomilnacipran ER in patients with major depressive disorder. J Clin Pscyhopharmacol. 2014; 34(1): 47-56.

25. Mago R, Forero G, Greenberg WM, et al. Safety and tolerability of levomilnacipran ER in major depressive disorder: results from an open-label, 48-week extension study. Clin Drug Investig. 2013; 33 (10): 761-771.

26. Nilsson ME, Suryawanshi S, Gassmann-Mayer C, et al. ColumbiaSuicide Severity Rating Scale scoring and data analysis guide. 2013; https://www.phenxtoolkit.org/toolkit_content/supplemental_ info/suicide/measures/CSSRS_Scoring and DataAnalysis Guide_Feb2013.pdf.

27. Baldessarini RJ, Lau WK, Sim J, et al. Suicidal risks in reports of long-term treatment trials for major depressive disorder. Int J Neuropsychopharmacol. 2015; 19(3): pyv107.

28. Borges G, Nock MK, Haro Abad JM, et al. Twelve-month prevalence of and risk factors for suicide attempts in the World Health Organization World Mental Health Surveys. JClin Psychiatry. 2010; 71(12): 1617-1628.

29. Lim AY, Lee AR, Hatim A, et al. Clinical and sociodemographic correlates of suicidality in patients with major depressive disorder from six Asian countries. BMC Psychiatry. 2014; 14: 37.

30. Trivedi MH, Morris DW, Wisniewski SR, et al. Clinical and sociodemographic characteristics associated with suicidal ideation in depressed outpatients. Can J Psychiatry. 2013; 58(2): 113-122.

31. Oquendo MA, Lizardi D, Greenwald S, et al. Rates of lifetime suicide attempt and rates of lifetime major depression in different ethnic groups in the United States. Acta Psychiatr Scand. 2004; 110(6): 446-451.

32. Lawrence RE, Oquendo MA, Stanley B. Religion and suicide risk: a systematic review. Arch Suicide Res. 2016; 20(1): 1-21. 